\title{
EXPLORATORY RESEARCH ON CULTURAL COMPUTING FOR HUMAN-COMPUTER INTERACTION. THE CASE OF SUSTAINABILITY.
}

\author{
Grimal, Lou (1); \\ di Loreto, Inès (2); \\ Troussier, Nadège (1) \\ 1: ICD, CREIDD, Université de Technologie de Troyes, 12 rue Marie Curie, 10004 Troyes, France; \\ 2: ICD, Tech-CICO, Université de Technologie de Troyes, 12 rue Marie Curie, 10004 Troyes, France
}

\begin{abstract}
The digital transition refers to the fact that information technology (IT) tools are used in all our activities on a daily basis. In this article, we will study the use of IT tools in engineering activities. It is possible to say that today IT tools accompany engineers in their professional practices. This presence of computing has also enabled the development and considerable changes in human-technologies interactions. Moreover, the socio-economic context has evolved considerably, and environmental issues have taken on an important role in engineering. We ask whether and to what extent these two contexts (digital and ecological) have changed the expectations of design professionals with regard to IT tools. Should the way of addressing the type of human-machine interaction in engineering tools be modified in depth? The objective of this paper is to understand what types of human-computer interaction would allow a more satisfying user experience for those future engineers who are using new technologies and marked by the ecological urgency. To do so, we will focus on a particular engineering context (design for sustainability) and a particular engineering practice (LCA practice).
\end{abstract}

Keywords: Cultural computing, Sustainability, Collaborative design, Human-Computer Interaction, Technology

\section{Contact:}

Grimal, Lou

Univesité de Technologie de Troyes

CREIDD

France

lou.grimal@utt.fr 


\section{INTRODUCTION}

The digital transition refers to the fact that information technology (IT) tools are used in all our activities on a daily basis. In this article, we will study the use of IT tools in engineering activities. It is possible to say that today IT tools accompany engineers in their professional practices. Two examples can be given: mechanical modelling activities are now carried out on software (computer-aided design); or, for example, environmental assessment calculations, which used to be carried out by hand for many months, are now carried out by algorithms in life cycle assessment (LCA) software (Boustead, 1996). In general, many companies have automated their production lines in order to meet productivity challenges. The monitoring of these production lines, via the integration of all the data in knowledge management software (product life cycle for instance), highlights the importance of data in this digital transition. Indeed, the years 2000-2010 marked the turning point for IT: "We estimate the beginning of the 'digital age' to be in 2002, when the world was first able to store more digital than analog information in its technological tools." (Hilbert, 2020). This presence of computing has also enabled the development and considerable changes in human-technologies interactions (also called human-computer interaction, $\mathrm{HCI}$ ): we have moved from man-computer interactions to multi-platform interactions via increasingly small and user-friendly technologies. Also, interaction via static texts has given way to diversified interactions (images, video, games, voice recognition).

Moreover, the socio-economic context has evolved considerably, and environmental issues have taken on an important role in engineering. We can even say that we have gone from a rather marginal environmental concern among engineers to a new generation trained and sensitive to ecological emergencies. Some engineering schools in France (for instance the universities of technologies, the INSA group) are modifying their training to integrate all the socio-ecological issues.

We ask whether and to what extent these two contexts (digital and ecological) have changed the expectations of design professionals with regard to IT tools. Should the way of addressing the type of human-machine interaction in engineering tools be modified in depth? The objective of this paper is to understand what types of human-computer interaction would allow a more satisfying user experience for those future engineers who are using new technologies and marked by the ecological urgency. To do so, we will focus on a particular engineering context (design for sustainability) and a particular engineering practice (LCA practice).

Thus, in this article we will try to better understand how HCI in LCA activities has evolved over the decades in order to imagine the potential evolution of interfaces and the use of these tools. In a first step we will present the different paradigms in HCI and why sustainability can be considered as a specific culture that can change HCI. In a second step we will see the role of HCI design in LCA tools (historical analysis) and the type of user experience of a young population (between 20 and 25 years old). In a third step, we will try some recommendations for HCI modifications.

\section{PARADIGMS AND CULTURAL CONTEXT}

This section helps us to define to which usage context HCI interaction must correspond to be compatible with a cultural context. A first part describes the history of paradigm evolutions in HCI. A second part deals with sustainability as a new cultural context (cultural evolution). The notion of context of design and use, and the notion of sustainability as a specific context are detailed.

\subsection{History of paradigm evolution in $\mathrm{HCl}$}

Thanks to (Rauterberg, 2006a), we have an overview of the growth and the development of HCI, from 1960s until the middle of the 2000s (Figure 1). Rauterberg offers 4 different paradigms. The fourth paradigm interests us because we want to know if adding cultural experience in the design of $\mathrm{HCI}$ is relevant to improve user experience of specific software's use among society. Table 1 sums up the main characteristics of each paradigm. 


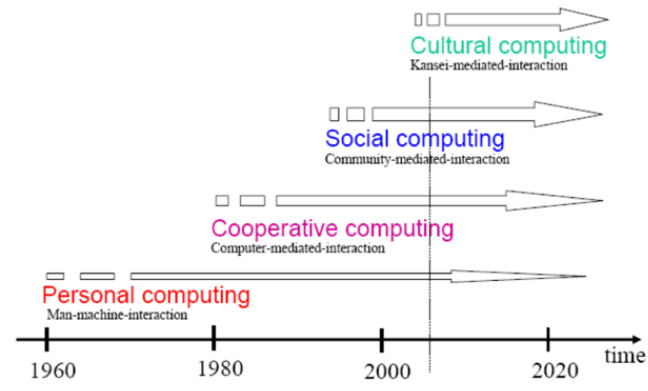

Figure 1. Historical perspective of the different $\mathrm{HCl}$ paradigm (Rauterberg, 2006a)

Table 1. Characteristics of each paradigm defined by (Rauterberg, 2006b)

\begin{tabular}{|l|l|}
\hline Name & \multicolumn{1}{|c|}{ HCI main characteristics } \\
\hline Personal & $\begin{array}{l}\text { The focus is made on the computer (mainly interaction } \\
\text { between one person and ond computer, also called man- } \\
\text { computer interaction in this article): } \\
\text { Scope: "Besides its limited reach of no collaboration, no } \\
\text { sharing and narrow vision, the personal computing extended } \\
\text { its domain from desktop to the industries without any } \\
\text { timeline" (Sharma } \text { et al., 2016) } \\
\text { Examples: “... attention was on personal productivity } \\
\text { applications, mainly text editing and spreadsheets" (Sharma } \\
\text { et al., 2016) }\end{array}$ \\
\hline $\begin{array}{l}\text { Cooperative } \\
\text { computing }\end{array}$ & $\begin{array}{l}\text { Scope: "Interactive multimedia was the main center of } \\
\text { attention in this phase" (Sharma et al., 2016) } \\
\text { Examples: Start of the Internet and development of mails, } \\
\text { newsgroups. Development of standards to allow this } \\
\text { communication. }\end{array}$ \\
\hline $\begin{array}{l}\text { Social } \\
\text { computing }\end{array}$ & $\begin{array}{l}\text { The focus is made on social interactions. } \\
\text { Scope: "Social Computing refers to applications and services } \\
\text { that aid combined action and social interaction on the } \\
\text { Internet" (Sharma } \text { et al., 2016). } \\
\text { Examples: the disappearing computer, the ease of use and } \\
\text { positive experience, the building of communities }\end{array}$ \\
\hline $\begin{array}{l}\text { Cultural } \\
\text { computing focus is made on the fact that "different cultures } \\
\text { worldwide need to have different approaches to address their } \\
\text { particular cultural determinants" (Sharma } \text { et al., 2016) } \\
\text { Scope: } 2 \text { characteristics which are the depth of semantic } \\
\text { involved and the use of implicit knowledge. This "allows for } \\
\text { much richer experience to be rendered" (Rauterberg). Some } \\
\text { unconscious cultural determinants are present. } \\
\text { Example: ZENetic computer, Alice in Wonderland }\end{array}$ \\
\hline
\end{tabular}

The cultural paradigm should allow an interaction between a human and a machine that refers (explicitly or implicitly) to the culture of the user. In the end, the person in his interaction with the machine will live an experience determined by his own culture. It therefore becomes obvious that knowing the determinants of a culture is very important for the design of interactive technologies. Thus, we will analyse in detail what are the determinants of a culture and of a context. In Rauterberg papers, culture is related to continents (Asian, European mostly). In this article, we are wondering if this notion of culture could be applied to sustainable communities (definition from (McDonald et al., 2009)). 


\subsection{Designing in a new cultural context}

In this section, we want to understand to what extend sustainable communities can be considered as a specific cultural context and what kind of HCI is best suited.

\subsubsection{What is a cultural context?}

Social computing (understood as a field, not a paradigm) "refers to the application of sociological understanding to the design of interactive systems" (Dourish, 2004). Thanks to this field, we know that the use of a technical tool depends on its context. The context is intended here as the social and technical elements of an environment. More specifically, as Dourish explains, a "context" can define:

- The tasks that the system is being used to perform.

- The reason for which the tasks are being carried out.

- The settings within which the work is conducted.

- Other factors that surround the user or the system.

One of the "other factors" is in the authors opinion the cultural factor. Culture is a broad word which is understood here as the representation of "very many of the intangible aspects of our values, customs and patterns of life" (Hawkes, 2001). According to Hawkes, culture has 3 aspects: (1) values, (2) processes and medium and (3) manifestation (see Appendix 1). We use these 3 aspects in the next subsection to define the specificities of the context of sustainability.

Before going further, we need to define what we mean by sustainability. In this article, sustainability refers to strong sustainability, understood as defined by (Dietz and Neumayer, 2007). Strong sustainability refers the non-capacity to substitute natural, social and physical and human capitals. This understanding of sustainability does correspond to a specific view of the world and a real paradigm shift from our current way of living (economic growth, (Vandeventer et al., 2019)). This does correspond to a specific cultural context.

\subsubsection{Specificities of a "sustainable context"}

In order to understand the specificities of a sustainable context and potential specificities in the interactions between technologies and humans, we have examined scientific articles analysing communities advocating these values. These articles describe the relationship between communities and technology. We mainly used the work of (Norton et al., 2019) to identify specificities of the technology that would correspond to a sustainable context. Through this article, we have identified several characteristics of these communities (in their values, functioning and results). This allows us to identify some of the characteristics of interactive technologies corresponding to this context (Appendix 1). We have clearly identified three of them:

- Confidence in the system: the data used to guide stakeholders in their practices are co-constructed (understandable).

- The user-friendliness of the system: the complexity of the system should not be too great so as not to limit its use. If the complexity is too high, the tool can lengthen the time to accomplish a task and the use of digital technology becomes counterproductive.

- Structural change: the system should not invite "heroic" individual behaviour for change but should conduct structural change.

We can see that digital tools corresponding to the majoritarian paradigm of their time have been widely used tools (for example social networks in the age of social computing). It would therefore be interesting to develop tools allowing an interaction compatible with the values of sustainability and with characteristics specific to the current paradigm in order to ensure a democratisation of the use of these tools. It is also an issue for sustainable communities to have access to tools that do not run counter to their values and practices.

\section{DOES HCI IN LCA ACTIVITIES CORRESPOND TO A SUSTAINABLE HCI?}

The goal of this section is to understand if sustainable values, practices or manifestations are integrated into LCA interfaces or contexts of use. To do this, two complementary approaches are used: (1) a historical analysis of LCA software to understand if LCA software evolution has followed the same dynamic as the ones described by Rauterberg for other digital tools, and (2) an analysis of students' expectancies on LCA to explore the gaps in the LCA tool - LCA practitioners' expectations. 


\subsection{Historical approach}

Table 2. Parallel between LCA software characteristics and $\mathrm{HCl}$ paradigms

\begin{tabular}{|c|c|}
\hline Name & HCI main characteristics \\
\hline Personal computing & $\begin{array}{l}\text { General message: } \\
\text { Most of the software is interactive, characterized by } \\
\text { the use of calculation software by a person who is } \\
\text { an expert in the life cycle analysis method. Software } \\
\text { was developed for a fixed-computer (GaBi and } \\
\text { SimaPro, 1990). } \\
\text { Characteristics described in the literature: } \\
\text { "Boustead's model has a reputation for slow } \\
\text { computation of results." (Rice et al., 1997) } \\
\text { "However, the current generation of tools is mainly } \\
\text { targeted at experts or users with a significant } \\
\text { background in industrial and environmental } \\
\text { processes" (Borrion et al., 2019) }\end{array}$ \\
\hline Cooperative computing & $\begin{array}{l}\text { General message: } \\
\text { Development of some features which allow a form } \\
\text { of collaboration in between practitioners. } \\
\text { Characteristics described in the literature: } \\
\text { The forum ask.openlca.org can be used by new } \\
\text { practitioners to get information about openLCA } \\
\text { functioning. } \\
\text { "Most packages do offer some form of graphical } \\
\text { output" (Rice et al., 1997) } \\
\text { "A facility available on some of the software } \\
\text { packages is that of network connection. This allows } \\
\text { several users access to the same database } \\
\text { simultaneously." (this concerns Ecobalance UK's } \\
\text { TEAMTM, SimaPro 3.1, PIA and LMS Eco- } \\
\text { Inventory). "Both "Boustead and Pira offer a site } \\
\text { license for the their software, allowing multiple } \\
\text { users, but the packages are not designed for network } \\
\text { operation." (Rice et al., 1997) }\end{array}$ \\
\hline $\begin{array}{l}\text { Social computing (we } \\
\text { based our research on the } 3 \\
\text { main characteristics given: } \\
\text { "the disappearing } \\
\text { computer; (2) the ease of } \\
\text { use and positive } \\
\text { experience and; (3) the } \\
\text { building of communities") } \\
\text { (Rauterberg, 2015) } \\
\text { Cultural computing for the } \\
\text { building of communities' } \\
\text { part. }\end{array}$ & $\begin{array}{l}\text { A focus on the positive experience: } \\
\text { Specific add-ones developed to communicate and } \\
\text { exchange on the results but also to improve } \\
\text { graphical representation and thus user experience. } \\
\text { SimaPro 9.1.1. (Release in September 2020) } \\
\text { provides a software as a service mode (PRé } \\
\text { Sustainability, 2021). You don't need anymore to } \\
\text { connect to Windows Server to get access to the } \\
\text { SimaPro Database Server. It is thus easier to use } \\
\text { that a client-mode. } \\
\text { Building of communities: } \\
\text { "This paper presents a novel process of developing } \\
\text { the LCA Calculator with inputs from community } \\
\text { members to support community infrastructure co- } \\
\text { design." } \\
\text { This last point can also be considered as a part of } \\
\text { cultural computing aspect for a sustainability HCI } \\
\text { context as the method used brings confidents in the } \\
\text { system. }\end{array}$ \\
\hline
\end{tabular}


LCA evolution is well documented (Boustead, 1996; Hunt et al., 1996) but the evolution of LCA software is quite hard to follow, as LCA software are mainly proprietary software produced by companies. Table 2 describes LCA software evolution and make a parallel with HCI paradigm.

There were several proposals to complete the methodology of LCA but very few on user-experience. Indeed, there has been a huge amount of work on LCA to integrate not only environmental but also economic impacts (Life cycle costing) and social (Social LCA) into LCA processes (Jørgensen, 2007; Woodward, 1997). We could see different kind of LCA emerging from those initiatives. Several works tried to locate the impacts in order to have a precise idea of the polluted areas (Rodriguez, 2007). Also, absolute sustainability by integrating planetary boundaries is currently explored by researchers (Bjørn et al., 2015). But even though the methodology is questioned, the way we use a LCA software is not actually a real discussion (the man-computer paradigm is still strongly present). Indeed, the humancomputer interaction has not moved for LCA specialists, even if some initiatives try to transform LCA as a collaborative software (example: last version of SimaPro, (PRé Sustainability, 2021)) to foster collaboration among life cycle analysts (cooperative paradigm). This lack of changes in LCA HCI might be an obstacle to the democratization of LCA among organizations. Also, it might not correspond to the interaction expect from the young generation of engineers.

LCA has emerged as a methodology in a world which was starting to realize how human activities could impact our planet. Earth System Sciences have gained maturity since it was coined in 1983 and scientists are now conscient of human impacts. Thus, our understanding of the world has considerably evolved but LCA methodology didn't really changed. Furthermore, as LCA was defined in a specific context of concern, it may not correspond anymore to the current context (ecological urgency). This could explain why it seems there is a few traces of cultural computing in LCA

\subsection{Future practitioners' approach}

A field study was carried out to understand the questioning of people in an interaction situation with LCA software. The aim was to understand whether their expectations were specific to cooperative, social or cultural interactions and to observe whether a gap existed between the expected interaction and the experienced interaction. As technologies evolve very quickly, we chose to select people who were comfortable in interacting with new technologies. These people were rather young (born between 1995 and 2000).

\subsubsection{Why future practitioners?}

We are not interested in the current practitioners because they are very much embedded in their daily professional habits. Instead, we are interested in the new generation of engineers and how this new generation conceives of human-technology interactions. The future engineers that we have observed have the characteristic of being interested in sustainability (specific choice of training and involvement in sustainable associative activities).

This section is focused on an observation of a pedagogical situation. Future practitioners are being observed. This group was chosen because they are in a learning phase of the environmental analysis method and the openLCA tool. Taking individuals who are in a learning period allows us to see the problems that arise very quickly for people wishing to use life cycle assessment software. This allows these problems to be brought up because they are expressed explicitly in the form of questions to the teachers. Also, we chose this situation to analyze as we tend to bring all the biases of the tool into the training and into the action that we are going to carry out.

The students' expectations were twofold: one part of them had a strong expectation of the software in terms of engineering and modelling, while another part of the remarks concerned the use of the software in a collective work. Students' expectations reveal what they think about the functions LCA software should content and the type of interaction they should experience with the software. It reveals a part of the culture they have and values they carry on technology.

\subsubsection{Description of the situation and method}

The focus of the observation was the understanding of LCA of a class of 30 Master students (second year of master). By groups of 5 to 7, the students were involved in a LCA project. In this study, a specific focus is made on their expectations from a LCA software (openLCA in this case study).

We observed the group of students during 3 tutorials of 2 hours each. During each tutorial we noted, questions of students on data, information on LCA and their remarks on the software. Also, following 
a qualitative analysis (Lejeune, 2019), we made an account, followed by a micro analysis, followed by a coding moment.

\subsubsection{In front of a LCA software (openLCA)}

This part deals with expectations of students on the software. Table 3 presents the different students remarks expressed when they were learning how to handle LCA software. The situation of each quote is explained on the same line. The recurrence of the questions asked was not recorded at the time the observation was made.

We can identify three different categories of issues: issues on data (situation $\mathrm{N}^{\circ} 1$ and 2), issues on information (situation $\mathrm{N}^{\circ} 3$ and 4), issues on modeling (situation $\mathrm{N}^{\circ} 5$ and 6). Some students were actually disappointed to realize they could not represent the entire complexity of their product through the software. Also, some students were surprised that all of the data from LCA databases were not complete and that sometimes, they had to choose a data which does not reflect the exact reality of their product. This expectancy of precision from the software and the information system around the field of LCA reveal the trust that young students put in engineering software. This expectancy is coherent with the current metaparadigm defined by Hilbert which is about having easily available data and knowledge.

The pedagogical situation was a project group which leads to collaborative work. Students faced the difficulty of working collaboratively on a LCA software. This difficulty was about the type of HCI that has been implemented in it. It is a man to computer interaction without any social activity needed on the software. This conclusion cannot be generalized without a similar training on other LCA software.

Table 3. Quotes of students which were learning how to do an LCA (September and November 2019

\begin{tabular}{|l|l|l|}
\hline $\mathrm{N}^{\circ}$ & \multicolumn{1}{|c|}{ Situation } & \multicolumn{1}{|c|}{ Quote from students } \\
\hline 1 & $\begin{array}{l}\text { Students were looking for a data in a LCA "We don't find the corresponding } \\
\text { database to complete their LCA. } \\
\text { data in EcoInvent"; "There is no } \\
\text { data, not even close [to the one } \\
\text { you are looking for], how do you } \\
\text { do it?" }\end{array}$ \\
\hline 2 & $\begin{array}{l}\text { Students were looking for the correct way to "Should we create a new data or } \\
\text { insert data into their model. } \\
\text { should we select one directly in } \\
\text { the database?" }\end{array}$ \\
\hline 3 & $\begin{array}{l}\text { Students were trying to reproduce a LCA from a a "It was not precised in the } \\
\text { LCA report found on the Internet. } \\
\text { report"; "We lack this } \\
\text { information" }\end{array}$ \\
\hline 4 & $\begin{array}{l}\text { Students were reading the description of each data } \\
\text { and were trying to understand if this data was the } \\
\text { closest to what they were looking for. }\end{array}$ & $\begin{array}{l}\text { do not understand it" } \\
\text { dtudents were trying to understand the logic of } \\
\text { modeling in openLCA. }\end{array}$ \\
\hline 6 & $\begin{array}{l}\text { Students were trying to understand the logic of } \\
\text { modeling in openLCA. } \\
\text { life?" }\end{array}$ \\
\hline
\end{tabular}

\section{WHAT IS THE PATHWAY FROM A PERSONAL TO A CULTURAL APPROACH FOR LCA SOFTWARE}

Inserting the cultural values specific to a sustainable community into life cycle analysis software would allow users to confront the values of this other paradigm and to experiment with other practices. It could also lead to changes in LCA methodology.

\subsection{Complexity and practices}

The complexity of the LCA software, the complexity of data access, the complexity of the data itself (in terms of data construction by experts and understanding by users), do not allow digital LCA tools to be user-friendly (convivial tools in the sense of used in (Vetter, 2018)) and to democratize their use. Moreover, LCA software use is a rather solitary practice (or in small groups) due in part to this 
complexity and to the software interface. LCA software does not allow for engaging a multitude of stakeholders in a multi-scale environmental assessment process.

In order to understand the complexity of this paradigm shift (from individual to cultural), we plan to test the use of LCA in different cultural contexts (at different levels of sustainability) and to identify the values embedded in this tool that are not conducive to an ecological transition in terms of values, practices and manifestations. In order to insert a sustainable HCI cultural approach into LCA, it might be interesting to assess the use of LCA in several sustainable contexts (weak and strong sustainability) to compare different approaches. In this way, the difference in use between different sustainable contexts can be measured and indications in terms of modification of LCA (LCA software, methodology, or others) can perhaps be formulated in order to democratize its use.

\subsection{Representation of the world}

LCA software is a tool born in a context of collaboration between research and industry and the idea of the software is to represent the inputs - outputs of a technical system, therefore, to represent a real situation in the digital tool. It also seems that the actors depend on what happens in the software (access to data, modelling mode, production of results) to act in real life. This is a practice that has existed for a long time in the industrial world and is part of this industrial culture (for example, we find the same aspect in product life cycle management). This practice is potentially problematic because it does can block action for change. As (Hansen, 2020) has said, "application is not where the action is" and this statement is more consistent with the objective of ecological transition. We can make the hypothesis that to address the cultural shift that is needed for sustainability, LCA interfaces should change one's representation of the world.

The question asked at the beginning of the article was the following "Should the way of addressing the type of human-machine interaction in engineering tools be modified in depth?" We could see that the three characteristics of interactive technologies (confidence in the system, user friendliness of the system and structural change) are not really present as the data are difficult to understand, the software in itself has a high level of complexity and LCA method does not question structural change (more environmental optimization).

\section{CONCLUSION}

In this paper we underlined that the socio-technical tool openLCA does not provide a satisfying user experience for a category of young designers. This digital tool appeared when human-computer interaction was mainly reduced to a text editing activity and calculation work. All those information allow us to conclude that openLCA software has been stuck in a man-computer paradigm specific to the 1970s and has not yet entered into a new paradigm (or not entirely in another paradigm). We don't know yet how this result can be generalized to all LCA software, but we have seen that a few LCA software provide multi-user exchange within the technology interaction.

As openLCA has remained mainly in a man-computer paradigm, we can also add that the HCI analysis of this environmental tool has highlighted the "individual-consumer" approach (Heitlinger et $a l ., 2013$ ) of the current LCA paradigm. Therefore, we need to move this approach towards a common concern for environmental issues. Borrion works can be considered as addressing this common concern by the co-construction by incorporating community users into the demarch. Further research on this new approach needs to be done before asserting it.

\section{ACKNOWLEDGMENTS}

"ACVnum: Life Cycle Assessment and Digital Transition" is co-financed by the European Union. Europe is committed to Champagne-Ardenne with the FEDER/FSE/IEJ Champagne Ardenne Operational Programme 2014-2020 / European Regional Development Fund.

\section{APPENDIX 1}

Indicators of a sustainable context. Table filled in thanks to the description of 2 permaculture communities (Norton et al, 2019). This table shows why and how the culture in a permaculture community is specific. Each indicator of Hawkes corresponds to observed elements. 


\begin{tabular}{|c|c|}
\hline Indicators & Elements of observation according to the literature \\
\hline \multicolumn{2}{|l|}{ Content } \\
\hline $\begin{array}{l}\text { Articulation of } \\
\text { communities' identity, } \\
\text { aspirations and/or history }\end{array}$ & $\begin{array}{l}\text { "the communities' long-term food sovereignty values } \\
\text { encourage the formation of an agrarian society in } \\
\text { place of the industrial society we have now." (Norton) }\end{array}$ \\
\hline $\begin{array}{l}\text { Stimulation of } \\
\text { community dialogue } \\
\text { around quality of life, } \\
\text { sustainability and respect } \\
\text { for diversity issues }\end{array}$ & $\begin{array}{l}\text { "The participants believed that by engaging in } \\
\text { permaculture, they could reduce their own and their } \\
\text { communities' ecological footprint, foster the } \\
\text { regeneration of natural resources, and be prepared } \\
\text { fora collapse."; (Norton) « Permaculture pictorials } \\
\text { and narratives have a shared theme of coupled human } \\
\text { and natural systems in which agriculture } \\
\text { functions. »(Norton) }\end{array}$ \\
\hline $\begin{array}{l}\text { Raising the profile of } \\
\text { universal human rights }\end{array}$ & $\begin{array}{l}\text { «The core permaculture ethics are: earth care, fair } \\
\text { share, and people care. » (Norton) }\end{array}$ \\
\hline \multicolumn{2}{|l|}{ Practice } \\
\hline $\begin{array}{l}\text { Level of communities' } \\
\text { fluency in cultural } \\
\text { processes and medium }\end{array}$ & $\begin{array}{l}\text { Willing to not have interactive technologies with a } \\
\text { high level of complexity. (Norton) } \\
\text { "the neglect of social interaction with people and } \\
\text { other living things in the physical environment when } \\
\text { using ITs" (Norton) }\end{array}$ \\
\hline $\begin{array}{l}\text { Level of communities' } \\
\text { access to cultural } \\
\text { processes and mediums }\end{array}$ & $\begin{array}{l}\text { «merging home and work life in such a way that } \\
\text { supports the natural rhythms of family life, } \\
\text { unmediated face-to-face interaction, being outside, } \\
\text { and a person's ability to multi-class in their roles. » } \\
\text { (Norton) }\end{array}$ \\
\hline $\begin{array}{l}\text { Level and types of } \\
\text { communities' action in } \\
\text { cultural processes and } \\
\text { mediums }\end{array}$ & $\begin{array}{l}\text { "peaceful protest to industrial and governmental } \\
\text { infrastructures that regulate their daily lives" (Norton) }\end{array}$ \\
\hline \multicolumn{2}{|l|}{ Results } \\
\hline $\begin{array}{l}\text { Manifestations of } \\
\text { community-initiated } \\
\text { cultural action }\end{array}$ & $\begin{array}{l}\text { "Selective use of technology, a form of } \\
\text { technological non-use", "for example, one participant } \\
\text { described his decision to use a basic phone rather than } \\
\text { a smart phone in order to avoid distractions and } \\
\text { improve his in-person interactions" (Norton) }\end{array}$ \\
\hline $\begin{array}{l}\text { Public access to } \\
\text { presented cultural activity }\end{array}$ & $\begin{array}{l}\text { IT available and understandable to anyone from the } \\
\text { community. }\end{array}$ \\
\hline Profile of cultural activity & $\begin{array}{l}\text { "A small subset of participants in the Live Oak } \\
\text { community met on a weekly or biweekly basis and } \\
\text { planted seeds and young plants in typically fallow } \\
\text { areas on both private and public property. Although } \\
\text { this was an illegal act, the guerrilla gardeners believed } \\
\text { that leaving the land fallow was more problematic } \\
\text { then trespassing or hijacking the space for their own } \\
\text { social agenda. » (Norton) }\end{array}$ \\
\hline $\begin{array}{l}\text { Range and type of public } \\
\text { facilities available for } \\
\text { cultural activities }\end{array}$ & $\begin{array}{l}\text { Facilities of the community, built in coherence with } \\
\text { permaculture principles. }\end{array}$ \\
\hline
\end{tabular}

\section{REFERENCES}

Bjørn, A., Diamond, M., Owsianiak, M., Verzat, B. and Hauschild, M.Z. (2015), "Strengthening the Link between Life Cycle Assessment and Indicators for Absolute Sustainability To Support Development within Planetary Boundaries", Environmental Science \& Technology, American Chemical Society, Vol. 49 No. 11, pp. 6370-6371. 
Borrion, A., Matsushita, J., Austen, K., Johnson, C. and Bell, S. (2019), "Development of LCA Calculator to support community infrastructure co-design", The International Journal of Life Cycle Assessment, Vol. 24 No. 7, pp. 1209-1221.

Boustead, I. (1996), "LCA — how it came about", The International Journal of Life Cycle Assessment, Vol. 1 No. 3, pp. 147-150.

Dietz, S. and Neumayer, E. (2007), "Weak and strong sustainability in the SEEA: Concepts and measurement", Ecological Economics, Vol. 61 No. 4, pp. 617-626.

Dourish, P. (2004), Where the Action Is: The Foundations of Embodied Interaction, MIT Press.

Hansen, A.-M.S. (2020), "The App Is Not Where the Action Is: Discussing Features of an Internal Communication System for a Permaculture Village", Proceedings of the 7th International Conference on ICT for Sustainability, Association for Computing Machinery, New York, NY, USA, pp. 275-284.

Hawkes, J. (2001), The Fourth Pillar of Sustainability: Culture's Essential Role in Public Planning, Common Ground.

Heitlinger, S., Bryan-Kinns, N. and Jefferies, J. (2013), "Sustainable HCI for grassroots urban food-growing communities", Proceedings of the 25th Australian Computer-Human Interaction Conference on Augmentation, Application, Innovation, Collaboration - $\mathrm{OzCHI}$ '13, presented at the the 25th Australian Computer-Human Interaction Conference, ACM Press, Adelaide, Australia, pp. 255-264.

Hilbert, M. (2020), "Digital technology and social change: the digital transformation of society from a historical perspective", Dialogues in Clinical Neuroscience, Vol. 22 No. 2, pp. 189-194.

Hunt, R.G., Franklin, W.E. and Hunt, R.G. (1996), "LCA - How it came about", The International Journal of Life Cycle Assessment, Vol. 1 No. 1, pp. 4-7.

Jørgensen, A. (2007), "The importance of the application context for the design of Social LCA methodology", presented at the Cycle 2007 : Towards a Life Cycle Economy, available at: https://orbit.dtu.dk/en/publications/the-importance-of-the-application-context-for-the-design-of-socia (accessed 6 December 2020).

Lejeune, C. (2019), Manuel d'analyse qualitative, De Boeck Superieur.

McDonald, S., Malys, N. and Malienè, V. (2009), "Urban Regeneration for Sustainable Communities: A Case Study", Technological and Economic Development of Economy, Vol. 15 No. 1, pp. 49-59.

Norton, J., Penzenstadler, B. and Tomlinson, B. (2019), "Implications of Grassroots Sustainable Agriculture Community Values on the Design of Information Systems", Proceedings of the ACM on Human-Computer Interaction, Vol. 3 No. CSCW, p. 34:1-34:22.

PRé Sustainability. (2021), "Software Installation", SimaPro Help Center, 4 March, available at: https://support.simapro.com/articles/Article/SimaPro-Installation (accessed 4 March 2021).

Rauterberg, M. (2006a), "Usability in the Future - explicit and implicit effects in cultural computing", in Heinecke, H.M. and Paul, H. (Eds.), Mensch Und Computer 2006, Oldenbourg Wissenschaftsverlag, München, available at:https://doi.org/10.1524/9783486841749.29.

Rauterberg, M. (2006b), "How to Assess the User's Experience in Cultural Computing”, p. 7.

Rauterberg, M. (2015), "From Personal to Cultural Computing: how to assess a cultural experience", p. 10.

Rice, G., Clift, R. and Burns, R. (1997), "Comparison of currently available european LCA software", The International Journal of Life Cycle Assessment, Vol. 2 No. 1, pp. 53-59.

Sharma, S., Bawa, S. and Lomash, H. (2016), "Proliferation of Social Computing: Cultural Computing Paradigm", International Journal of Computer Applications, Vol. 137 No. 9, pp. 27-30.

Vandeventer, J.S., Cattaneo, C. and Zografos, C. (2019), “A Degrowth Transition: Pathways for the Degrowth Niche to Replace the Capitalist-Growth Regime”, Ecological Economics, Vol. 156, pp. 272-286.

Vetter, A. (2018), "The Matrix of Convivial Technology - Assessing technologies for degrowth", Journal of Cleaner Production, Vol. 197, pp. 1778-1786.

Woodward, D.G. (1997), "Life cycle costing - Theory, information acquisition and application", International Journal of Project Management, Vol. 15 No. 6, pp. 335-344. 